\title{
Salvador Giner. Ideas cabales. Madrid: Alianza Editorial, 2018
}

\author{
Marc Grau-Grau \\ Women and Public Policy Program, Harvard Kennedy School, Estados Unidos \\ Universidad Internacional de Cataluña, España \\ marc_grau-grau@hks.harvard.edu; mgraug@uic.cat
}

Salvador Giner de San Julián [1934-2019] nos ha dejado un valioso legado, materializado en distintas formas. Giner no solo nos dejó obras como Historia del pensamiento social (1967), publicado a los 33 años, Sociología (1969), El progreso de la conciencia sociológica (1974), Sociedad masa (1979), El destino de la libertad (1987), El origen de la moral (2012) o Sociología del mal (2015), sino que a la vez vistió, inhaló vida o presidió instituciones como la Federación Española de Sociología (FES), el Instituto de Estudios Sociales Avanzados (IESA) del CSIC o el Institut d'Estudis Catalans (IEC), piezas cabales para el avance del conocimiento social. Un hombre de reflexión, y acción.

Ideas cabales ha sido su última obra. El libro, publicado por Alianza Editorial como ya lo fueron Carisma y razón (2003a) y Diccionario de Sociología (2013), es un glosario dedicado al intrépido lector. A usted. En otras palabras, es un "glossarium significationum" (p.7), un léxico confeccionado para cualquier lector de buena fe (p. 8), dividido en tres partes. Primero, un proemio firmado desde su querida Córdova, seguido por una Postdata al Proemio. Segundo, el propio glosario, siendo éste la esencia del libro con casi quinientas entradas. Tercero, unas advertencias y agradecimientos finales. En total, 337 páginas unidas "por una única visión [que] aúna la pluralidad de las ideas atesoradas" (p. 335). Es nuestra tarea y deber como lectores, comprender el hilo que cose todas las ideas desbrozadas por el pensador catalán.

Giner presenta su libro no como un diccionario, sino como un Thesaurus. Éste, no obstante, no sigue una estructura jerarquizada, sino alfabética. Empieza por ABANDONO y termina en ZURRA. Nuestro lexicógrafo es buen conocedor de los diccionarios ya sea como autor, como partícipe en grandes diccionarios, como es el caso del nuevo Diccionari de la Llengua Catalana (2007) firmando su prólogo como presidente del IEC, o como lector omnívoro, destacando el "insuperable diccionario" de María Moliner, el diccionario de filosofía de Ferrater Mora, así como otros lides lexicográficas expuestas en su obra.

El lector encontrará en la exposición de cada idea cabal, algunas palabras en cursiva, significando que éstas poseen, a su vez, una entrada para ellas mismas. Algunas ideas 
cabales son acompañadas por fuentes y referencias, otras no. En total, encontramos más de trescientas referencias que abren el apetito del lector. Estas se mueven por distintos campos: la sociológica clásica (Durkheim, Simmel, Tönnies, Weber), la sociológica contemporánea (presentado, por ejemplo, obras de Helena Béjar), la filosofía (Nietzsche, Ortega, Spinoza), la literatura universal (Camus, Cervantes, Molière, Pla) o la mística de San Juan de la Cruz o Santa Teresa de Jesús. Para colofón, algunas ideas cabales son acompañadas por coplas provenientes de dos fuentes: las Coplas de Nadie de Francisco Díaz Vázquez (2015), y la Colección de cantes flamencos recogido por Demófilo (2011), seudónimo de Antonio Machado y Álvarez.

Entre los centenares de entradas en Ideas cabales, encontramos al menos tres grandes virtudes en Giner: una lucidez lacónica, una crítica no-derrotista, y una visión panóptica. A su vez, entre líneas podemos leer, al menos también tres interesantes tensiones entre distintos elementos que pueden ayudar a comprender mejor nuestra realidad social: la tensión entre objetividad y moralidad, la tensión entre ciencia y sabiduría, y la tensión entre la inteligencia y la bondad.

Lucidez lacónica. Giner muestra una claridad mental envidiable para comprender elementos claves (ideas cabales) de la realidad social, y exponerlo y compartirlo de forma breve, austera, lacónica. Tiene la capacidad de sintetizar lo profundo. Él mismo destaca esta habilidad en otros autores, como es el caso de Albert Hirschman (19152012), quien posee "la amable virtud de la brevedad y elegancia de quien escribe en tercera o cuarta lengua". En Giner, encontramos esta lucidez lacónica en muchas definiciones. Algunos ejemplos serían CONCIENCIA definida como "percatación de una realidad asumida" (p. 80), DIGNIDAD como "propiedad moral de todo ser humano" (p. 113), o PASOTISMO presentada como “indiferencia convertida en doctrina" (p. 234).

Crítica-no derrotista. A su vez, Giner, es un crítico de nuestros tiempos modernos. En su definición de ZEITGEIST, "el espíritu de una época", añade "respeto a nuestro tiempo, que empezó con estrépito de muros derruidos en 1989, y cubre ya dos decenios del siglo XXI, se caracteriza por carecer de él. El espíritu de nuestro tiempo es no tenerlo" (p. 332). El autor que define el espíritu de nuestro tiempo por su ausencia, y quien presenta las olimpiadas como orgías nacionalistas (p. 103), la BENEFICENCIA "como la entrega de una parte ínfima de la propiedad para el bien ajeno" (p. 55) o la BLOGOSFERA como una "panoplia de aparatos blogosféricos [que] ha supuesto el nacimiento de una humanidad absorta en ella" (p.57), puede usar el recurso irónico, pero nunca sarcástico. Crítica una sociedad centrada en el yo, en el NOSOTROS que "enaltece el mal" (p. 226), y poco en el otro, en los OTROS, también definido en su glosario. El pensador dispone, no obstante, de una especial cualidad a la hora de presentar su crítica, sin llegar nunca a invitar al lector a caer en el derrotismo, o catastrofismo. Giner destila su crítica, inyectando sutilmente coraje y clarividencia, para que una vez "rasgado" el telón, sigamos trabajando para mejorar nuestra realidad social.

Visión panóptica. Una de las grandes cualidades de Giner ha sido siempre su visión panóptica, como ya demostró desde joven con Historia del pensamiento social (1967), o más adelante con las ediciones de Teoría sociológica clásica (2001) o Teoría sociológica moderna (2003b). Ha sido siempre un decidido en querer mostrar la fotografía completa, aun y los riesgos que puede entrañar. En esta nítida fotografía o elegante topografía, Giner aprovecha para presentar algunas lagunas importantes en el terreno, que pueden ser útiles para jóvenes investigadores, y obviamente para todos aquellos inquietos y curiosos. El sociólogo catalán informa que, al menos, carecemos de un Tratado del ABANDONO (p.11), un Tratado del AGUAFESTISMO (p.22), un Tratado del DISTANCIAMIENTO (p.118), un Tratado de la NINGUNOLOGíA (p.225), y hasta de Tratado de la PECADOLOGíA (p. 236). ¿Porque abandonamos cosas, personas, y sueños? ¿Por qué aguamos la fiesta a otro, o a otros? ¿Por qué nos distanciamos? ¿Por qué ninguneamos al vecino, la colega, a la persona que espera en el supermercado? ¿Por qué pecamos? Y así, jugando con 
todo el largo entramado de quienes, cómo, porque, mecanismos, estructuras sociales, actitudes, etc. Entre sus líneas, podríamos, finalmente, exponer al menos tres tipos de tensiones que pueden ayudar a comprender mejor posibles las intenciones que percibo del libro, quizás erróneas.

Tensión (necesaria) entre la objetividad y moralidad. Podemos tender a pensar que la objetividad y la neutralidad van de la mano. Giner nos invita a ver su glosario como un esfuerzo por presentar cada idea cabal de la manera más objetiva posible: "la objetividad es el tributo que ofrecemos a la verdad (p. 8)". Sin embargo, se apresura a comentar que su exposición que aspira a la objetividad, no tiene por qué ser moralmente neutra. La moral siempre ha preocupado a Giner, y así lo podemos ver en sus obras Carisma y Razón. La estructura de la moral en la sociedad moderna (2003a) o más recientemente en Origen de la moral (2012), esforzándose para que la filosofía moral asuma la aportación de la sociología. La moral es, en parte, social. Y, por lo tanto, Giner, aspira siempre a la verdad, la objetividad, sin renunciar a la moralidad: "A la objetividad desapasionada aspiran las exploraciones y definiciones recogidas en el léxico. A la neutralidad nunca" (p. 8).

Tensión (necesaria) entre la ciencia y sabiduría. Giner presente con su talante lacónico la CIENCIA como "concepto sacrosanto en la modernidad" definido como "la búsqueda del conocimiento de la realidad mediante la indagación empírica, el examen racional, y la crítica abierta y pública de cada aseveración" (p. 71). Nuestro lexicógrafo aprovecha para desaprobar o el menos clasificar como muy necia, la distinción entre las ciencias naturales, consideradas como más sólidas, y las ciencias sociales, muy a menudo vistas como débiles. Será ciencia, si cumple los requisitos de toda ciencia. Mientras que a la vez se pregunta ¿y qué tendrá que ver la ciencia con la sabiduría? Ésta, la SABIDURÍA, es el “conocimiento de la verdad". El científico no es necesariamente sabio. El sabio, obviamente, tampoco tiene porque ser necesariamente científico. Tal y como afirma Giner, "el aumento de nuestro conocimiento objetivo de la realidad, logro indiscutible de la ciencia y de toda buena filosofía, no siempre nos hace mejores moralmente ni más sabios" (p. 281).

Tensión (necesaria) entre la inteligencia y la bondad. Otra tercera tensión discurre entre la inteligencia y la bondad. Leemos que "la bondad es más necesaria y admirable que la inteligencia" (p.61). La INTELIGENCIA es la "capacidad de entender, comprender, conceptualizar y expresar lo apercibido e incorporado a la mente y conciencia" ( $p$. 182). Esta comprensión del mundo, de la realidad social, y de la existencia, no implica necesariamente más bondad. Entender que los lazos comunitarios se desatan no tiene porqué llevarnos a querer atarlos. Son vasos no necesariamente comunicantes. El AMOR, presentado como "afecto intenso y noble hacia otro u otros (p.34)", tiene su fuerza en el otro, en los OTROS. De hecho, Giner presenta la FRATERNIDAD como la "vecina del amor" (p.35). Encontramos a un Giner que delante de la encrucijada inteligencia/bondad, opta por la última, definiendo las Bienaventuranzas (p. 93), como el discurso más radical y revolucionario de todos los conocidos.

Por lo tanto, el libro reseñado es una ventana de aire fresco para seguir comprendiendo a la persona, "el objetivo conocido más complejo del mundo" (p. 164) y su realidad social. En definitiva, Ideas Cabales es una llamada a la IGNOTOFILIA, amor a lo desconocido (p.21) para contrarrestar la AGNOTOFILIA, el amor a la ignorancia que es el mal endémico de nuestra sociedad humana. Es necesario, por lo tanto, fomentar en todos los ámbitos, en todas las personas, el amor a lo desconocido (y al desconocido), que, estimulado por la curiosidad, puede llevar a descubrir, y consecuentemente, al saber. Por lo tanto, concluye nuestro autor, pocos asuntos hay de interés común más importantes que la educación. Que los lectores sepamos aprovechar la última obra de Giner y que sus Ideas cabales sean una llamada refrescante al saber. Un saber entendido como estímulo, proceso y fin. 


\section{Referencias}

Díaz Vázquez, F. (2015). Coplas de Nadie. Libros de la Herida.

Giner, S. (1967). Historia del pensamiento social. Ariel.

Giner, S. (1969). Sociologia. Ediciones Península.

Giner, S. (1974). El progreso de la conciencia sociológica. Ediciones Península.

Giner, S. (1979). Sociedad masa: crítica del pensamiento conservador. Edicions 62.

Giner, S. (1987). El destino de la libertad. Una reflexión frente al milenio. Espasa Calpe.

Giner, S. (2001). Teoría sociológica clásica. Ariel.

Giner, S. (2003a). Carisma y razón. La estructura moral de la sociedad moderna. Alianza Editorial.

Giner, S. (2003b). Teoría sociológica moderna. Ariel.

Giner, S. (2012). El origen de la moral. Ética y valores en la sociedad actual. Ediciones Península.

Giner, S. (2015). Sociologia del Mal. La Catarata.

Giner, S., Lamo, E., \& Torres, C. (2013). Diccionario de Sociología. Alianza Editorial.

Machado y Álvarez, A. (Demófilo). (2011). Colección de cantes flamencos. Extramuros. 